\title{
Las nuevas formas de la guerra y el cuerpo de las mujeres
}

Rita Laura Segato*

Resumen: Las nuevas formas de la guerra, caracterizadas por la informalidad, se despliegan hoy en un espacio intersticial que podemos caracterizar como para-estatal porque se encuentra controlado por corporaciones armadas con participación de efectivos estatales y para estatales. En esa esfera de para-estatalidad en franca expansión, la violencia contra las mujeres ha dejado de ser un efecto colateral de la guerra y se ha transformado en un objetivo estratégico de este nuevo escenario bélico. Se examinan aquí las transformaciones históricas que circundan la informalización de la guerra y la centralidad que asume en ellas una "pedagogía de la crueldad" contra aquéllos que no juegan el papel de antagonistas armados - mujeres y niños - en los enfrentamientos.

Palabras llave: guerras, violencia de género, femigenocidio, territorialidad, para-estatalidad.

\section{Introducción}

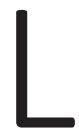

as guerras actuales se han transformado de forma substantiva. No se destinan a un término y su meta no es la paz, en cualquiera de sus versiones. El proyecto de la guerra es hoy, para sus administradores, un proyecto a largo plazo, sin victorias ni derrotas conclusivas. Casi podría decirse que el plan es que se transformen, en muchas regiones del mundo, en una forma de existencia. Una de las razones para esto es que, con la progresiva pérdida de control sobre la economía global y el desplazamiento del epicentro del capital, la potencia imperial ve en la proliferación de las guerras su última forma de dominio. Para esta fase apocalíptica, los Estados Unidos vienen preparándose desde hace por lo menos dos décadas, con inversiones desproporcionales en la investigación científico tecnológica y en la industria bélica. La guerra es su último naipe frente a la pérdida progresiva de dominio. Más con Clausewitz que con Foucault, hoy la guerra aflora y se vuelve conspicua como la materialidad última e irreductible horizonte de toda política, es decir, como la política por otros medios.

Guerra despojadora y lucrativa, sin principio y sin final, de la emergencia a la permanencia. Los templos de los pueblos derrotados ya no son soterrados bajo los nuevos templos construidos por los pueblos victoriosos; sus ruinas expuestas son el locus en que se exhibe la potencia predadora del más fuerte. En este nuevo escenario bélico mundial, las guerras de nuestro continente son de tipo no convencional, y hacen del mismo el espacio más violento del planeta en términos de guerras no libradas formalmente entre estados, aunque en éstas participen efectivos y corpora-

\author{
* Antropóloga, \\ professora dos \\ Programas de \\ Pós-Graduação \\ em Bioética e em \\ Direito Humanos \\ da Universidade \\ de Brasilia. \\ <ritalsegato@gmail. \\ com>.
}


ciones armadas estatales y no estatales. En él se encuentra la ciudad más violenta del globo en términos de homicidios por cada 100.000 habitantes - San Pedro Sula, en Honduras - y el país más violento - Brasil, con once de las treinta ciudades más violentas del mundo (Unodoc, Naciones Unidas, 2014), seguido por México.

Trato aquí del impacto de las nuevas formas de la guerra en la vida de las mujeres. La guerra hoy se ha transformado, y algunos especialistas en su historia comienzan a examinar su diseño y listar sus nuevas características. Desde las guerras tribales hasta las guerras convencionales que ocurrieron en la historia de la humanidad hasta la primera mitad del siglo XX, el cuerpo de las mujeres, qua territorio, acompañó el destino de las conquistas y anexiones de las comarcas enemigas, inseminados por la violación de los ejércitos de ocupación. Hoy, ese destino ha sufrido una mutación por razones que tenemos pendiente examinar: su destrucción con exceso de crueldad, su expoliación hasta el último vestigio de vida, su tortura hasta la muerte. La rapiña que se desata sobre lo femenino se manifiesta tanto en formas de destrucción corporal sin precedentes como en las formas de trata y comercialización de lo que estos cuerpos puedan ofrecer, hasta el último límite. A pesar de todas las victorias en el campo del Estado y de la multiplicación de leyes y políticas públicas de protección para las mujeres, su vulnerabilidad frente a la violencia ha aumentado, especialmente la ocupación depredadora de los cuerpos femeninos o feminizados en el contexto de las nuevas guerras.

Aún en un panorama que enfatiza las continuidades del destino de las mujeres en la historia de las guerras, como es el caso del ya clásico texto dela magistrada costarricense Elizabeth Odio, jueza del Tribunal Internacional para juzgar los crímenes de la antigua Yugoslavia y primera jueza del Tribunal Penal Internacional, la autora reconoce que, a pesar del surgimiento y la firma de Convenios humanitarios con cláusulas para la protección de las mujeres en la guerra, en los conflictos del siglo XX no solo ha empeorado la situación para los civiles y, en especial para las mujeres y los niños, sino también la violación y los abusos sexuales "parecen haber aumentado en sadismo" (Odio, 2001: 101). En mi análisis, intento demostrar la existencia de un quiebre o discontinuidad en los paradigmas bélicos del presente caracterizados por el predominio de la informalidad y de un accionar que puede ser descripto como claramente para-estatal aun en los casos en que el Estado sea la agencia propulsora y sostenedora de ese accionar. Sostengo que en el papel y función asignado al cuerpo femenino o feminizado en las guerras de hoy se delata una rotación o viraje del propio modelo bélico.

Las guerras de la antigua Yugoslavia y de Rwanda son paradigmáticas de estas transformación e inauguran un nuevo tipo de accionar bélico en el que la agresión sexual pasa a ocupar una posición central como arma de guerra productora de crueldad 
y letalidad, dentro de una forma de daño letal que es simultáneamente material y moral. La impresión que emerge de ese nuevo accionar bélico es que la agresión, la dominación y la rapiña sexual ya no son, como fueron anteriormente, complementos de la guerra, daños colaterales, sino que han adquirido centralidad en la estrategia bélica. Precisamente por esa mutación, después de su invisibilidad inicial y como consecuencia de la presión de entidades de derechos humanos, "la violación y la violencia sexual" ("violación y otros actos inhumanos") practicadas como parte de un proceso de ocupación, exterminio o sujeción de un pueblo por otro, fueron siendo incorporadas paulatinamente a la legislación sobre crímenes de guerra, genocidio y lesa humanidad. La violación, "como tortura y esclavitud", y "otras formas de violencia sexual, como la desnudez forzada y el entretenimiento sexual, como tratamiento inhumano", en el Estatuto del Tribunal Internacional Ad Hoc para la Ex Yugoeslavia y, más tarde, como "actos constitutivos de genocidio" en el Estatuto del Tribunal Penal Internacional para Ruanda, pasando allí también a ser consideradas crímenes de guerra y tipos de tratamiento humillante y degradante ("atentados contra la dignidad personal, en particular violación, tratos humillantes y degradantes, y abusos deshonestos") (Copelon, 2000: 8 y 11). Éste fue también el camino por el cual se tipificaron finalmente una diversidad de crímenes sexuales en el Estatuto de Roma, que rige los procesos del Tribunal Penal Internacional.

Para comprender las nuevas guerras, es necesario primero pasar revista a los cambios contextuales que las hacen posibles porque afectan la estructura de los conflictos. Ellos son cambios consonantes con una economía de mercado global, en una modernidad tardía, en medio a ciclos críticos del capitalismo cada vez más frecuentes, a la inestabilidad política, la decadencia de la "democracia real", y la porosidad de los Estados y de los territorios nacionales que administran. El contexto de ese cambio de la guerra, que ya no responde al conflicto convencional entre Estados Nacionales característico de las conflagraciones del siglo XX, es también el del cambio de muchas otras dimensiones de la vida: la territorialidad, la política, el Estado, la economía y el propio patriarcado. Paso a continuación revista de las dimensiones contextuales de la guerra que se han transformado, confiriendo a la escena bélica una nueva estructura y asignando al cuerpo femenino o feminizado un papel nuevo que lo transfiere de una posición marginal a una posición central.

\section{Informalización de las normas bélicas contemporáneas}

La nueva conflictividad informal y las guerras no-convencionales configuran una escena que se expande en el mundo y, en especial, en América Latina, con muchas faces. El crimen organizado; las guerras represivas para-estatales de los regímenes dictatoriales, con sus fuerzas para-militares o sus fuerzas de seguridad oficiales actuando para-militarmente; la represión policial, con su accionar siempre, ineludiblemente, 
en un registro estatal y en un registro para-estatal; el accionar represivo y truculento de las fuerzas de seguridad privadas que custodian las grandes obras; las compañías contratadas en la tercerización de la guerra; las así llamadas "guerras internas" de los países o "el conflicto armado" son parte de ese universo bélico con bajos niveles de formalización. No comportan ni uniformes ni insignias o estandartes, ni territorios estatalmente delimitados, ni rituales y ceremoniales que marcan la "declaración de guerra" o armisticios y capitulaciones de derrota, y aun cuando hay ceses del fuego y treguas sobreentendidas, estas últimas son siempre confusas, provisorias e inestables, y nunca acatadas por todos los subgrupos de miembros de las corporaciones armadas enfrentadas. Estos conflictos, en la práctica, no tienen un comienzo y un final, y no ocurren dentro de límites temporales y espaciales claros.

Los grupos o corporaciones armadas que se enfrentan en esta nueva modalidad de la guerra son facciones, bandos, maras, patotas, gangs, grupos tribales, mafias, mercenarios corporativos y fuerzas para-estatales y estatales de varios tipos -incluyendo aquí los agentes de la así llamada "seguridad pública" en el ejercicio de su discrecionalidad en Estados cuya "duplicidad" creciente ya no se disimula (volveré más tarde sobre el tema de la dualidad del Estado). Se trata de un escenario difusamente bélico, en el que las acciones violentas son de tipo criminal o se encuentran en el liminar de la criminalidad, y son "corporativas", pues, la responsabilidad sobre las mismas es de los miembros armados de una corporación de tipo para-estatal y de sus "cabezas" o dirigentes, de los que emana el mandato de la misma a sus perpetradores. Dario AzzeIlini, en su libro El negocio de la guerra (Azzellini, 2005) y en una exhaustiva entrevista en que sintetiza sus hallazgos (Azzellini, 2007) enfatiza la diferencia o "discontinuidad" de la historia bélica, como la he llamado más arriba, al notar que antes los mercenarios eran individuos o pequeños grupos de personas, marginales con relación a la conducción de la guerra, pero hoy constituyen un cuantioso capital humano bélico administrado dentro del rubro "recursos humanos" por empresas de la guerra de grande porte, y su accionar se ve libre de los códigos que constriñen el comportamiento de las fuerzas propiamente estatales.

Esta violencia corporativa y anómica se expresa de forma privilegiada en el cuerpo de las mujeres, y esta expresividad denota precisamente el esprit-de-corps de quienes la perpetran, se "escribe" en el cuerpo de las mujeres victimizadas por la conflictividad informal al hacer de sus cuerpos el bastidor en el que la estructura de la guerra se manifiesta (Segato, 2003; 2006; 2011-a; 2012; 2013). En otras palabras, en estas guerras de bajos niveles de formalización, parece estar difundiéndose una convención o código: la afirmación de la capacidad letal de las facciones antagónicas en lo que llamé "la escritura en el cuerpo de las mujeres" (Segato, 2006; 2013), de forma genérica y por su asociación con la jurisdicción enemiga, como documento eficiente de la efímera victoria sobre la moral del antagonista. Y ¿̇por qué en las mujeres y por qué por medio 
de formas sexualizadas de agresión? Porque es en la violencia ejecutada por medios sexuales donde se afirma la destrucción moral del enemigo, cuando no puede ser escenificada mediante la firma pública de un documento formal de rendición. En este contexto, el cuerpo de la mujer es el bastidor o soporte en que se escribe la derrota moral del enemigo.

Es muy importante también hacer notar que no es ésta una agresión al cuerpo antagonista, al cuerpo del sicario de la facción enemiga, sino otra cosa. Los agredidos son cuerpos frágiles, no son cuerpos guerreros. Por eso manifiestan tan bien, con su sufrimiento, la expresividad misma de la amenaza truculenta lanzada a toda la colectividad. Un mensaje de ilimitada capacidad violenta y de bajos umbrales de sensibilidad humana. En la acción para-estatal de estos grupos es todavía más crítica la necesidad de demostrar esa ausencia de límites en la ejecución de acciones crueles, ya que no se dispone de otros documentos o insignias que designen quién detenta la autoridad jurisdiccional. Por un lado, la truculencia es la única garantía del control sobre territorios y cuerpos, y de cuerpos como territorios, y, por el otro, la pedagogía de la crueldad es la estrategia de reproducción del sistema. Con la crueldad aplicada a cuerpos no guerreros, sobre todo, se aísla y potencia la función propiamente expresiva de estos crímenes, función que, como he destacado en todos mis análisis anteriores, es inherente e indisociable en todos los tipos de violencia de género.

Estamos frente a crímenes de guerra, de una nueva forma de la guerra. La violación y la tortura sexual de mujeres y, en algunos casos, de niños y jóvenes, son crímenes de guerra en el contexto de las nuevas formas de la conflictividad propios de un continente de para-estatalidad en expansión, ya que son formas de violencia inherente e indisociable de la dimensión represiva del Estado contra los disidentes y contra los excluidos pobres y no-blancos; de la para-estatalidad propia del accionar bélico de las corporaciones militares privadas; y de la acción de los sicariatos - constituidos por pandillas y maras - que actúan en las barriadas periféricas de las grandes ciudades latinoamericanas $-y$, posiblemente, en el contexto subterráneo de la interconexión entre todos ellos. Allí, la finalidad es otra, diferente a la de los crímenes ordinarios de género o crímenes de la intimidad, aunque los elementos centrales a la configuración de la estructura patriarcal permanecen y son determinantes como, por ejemplo, lo que he descripto como el mandato de violación emanado de la cofradía masculina en el horizonte mental del violador común (Segato, 2003), que acaba siendo análogo al mandato de la pandilla o corporación armada que ordena reducir, subordinar, masacrar moralmente mediante la violación sexual de la mujer asociada a la facción antagonista o al niño que no se deja reclutar o que desobedece.

Es necesario recordar y reafirmar que éstos no son crímenes de motivación sexual, como los medios y las autoridades siempre insisten en decir para privatizar y, de esa 
forma, banalizar este tipo de violencia ante el sentido común de la opinión pública, sino crímenes de guerra, de una guerra que debe ser urgentemente redefinida, analizada bajo una nueva luz y a partir de otros modelos, e incorporada con nuevas categorías jurídicas en el Derecho y, muy especialmente, en el Derecho Internacional, es decir, en el campo de los Derechos Humanos y de la Justicia Humanitaria.

Una nueva generación de investigadores comienza a trazar las características de esta nueva modalidad de la guerra. Elementos que aparecen por ellos relevados son, precisamente, su informalización a medida que los conflictos dejan de serlo entre Estados Nacionales. Para Herfried Münkler, después de un largo periodo de estatización, ha ocurrido un retorno a la privatización y comercialización de las guerras. Este autor, al igual que Azzellini, también subraya su carácter lucrativo, así como la utilización de mercenarios y de niños como recursos humanos, su transnacionalización y su "desmilitarización", o sea, su informalización (Münkler, 2003). En The new wars, Münkler (2005) habla de la transferencia del control de la guerra de ejércitos de Estados nacionales a bandas comerciales pertenecientes a señores de la guerra, y a la participación de Estados, para-Estados y actores privados (Münkler, 2005: 3). Con estas transformaciones, el antiguo límite claramente trazado entre la violencia permisible en las acciones de guerra y la violencia criminal (Münkler, 2005: 40) se disuelve. En la paradigmática guerra de los nuevos tiempos que fue la de la antigua Yugoslavia, tanto en el lado Serbio como en el Bosnio, "el submundo de las grandes ciudades", sus matones y sus pandillas mafiosas, "ocupaban las posiciones clave en los grupos para-militares" (Münkler, 2005).

Pero lo que es más relevante para nuestro tema aquí es su coincidencia en la discontinuidad que nota en el tratamiento de las mujeres y los niños en las nuevas formas de la guerra. Si las mujeres siempre fueron tratadas como "botín de guerra, el premio de la victoria, el objeto sexual de los soldados", "sin embargo, la forma extrema de generalización que presenta la violencia contra las mujeres como un fenómeno siempre idéntico, una constante antropológica, minimiza la extensión en que esto ha variado históricamente tanto en escala como en intensidad"(Münkler, 2005: 81). "Evidentemente siembre hubo violencia contra las mujeres en las guerras clásicas entre Estados, pero desde el siglo dieciocho, como mínimo, eso ha sido considerado como crimen de guerra por el cual la penalidad ha sido usualmente la pena de muerte", mientras que las guerras de las últimas dos décadas no demuestran ningún respeto por ningún tipo de instrumento o reglamento para la protección de mujeres y niños (Münkler, 2005: 82). El autor destaca aquí la eficacia de la violación como instrumento de limpieza étnica de bajo costo: una forma de eliminación sin el costo de las bombas ni la reacción de los Estados vecinos (Münkler, 2005: 83). Los tres pasos de la disolución de un pueblo sin genocidio consisten, para Münkler, en la ejecución pública de sus figuras prominentes, la destrucción 
de sus templos, construcciones sagradas y monumentos culturales, y la violación sistemática y el embarazo forzado de sus mujeres. Con esto, de forma eficaz y "económica" se substituye la batalla, de las guerras convencionales, por la masacre de las guerras contemporáneas (Münkler, 2005: 83). El autor también menciona la emasculación y humillación que retiran la asertividad de los vencidos por no poder proteger a "sus" mujeres, lo que torna evidente que se trata de un ataque dirigido al enemigo "por medio de la violencia infligida en el cuerpo de la mujer" y ya no, como antes, "golpeando los órganos de poder del Estado" (Münkler, 2005: 85). Y por el hecho de esa práctica haberse extendido hoy a sociedades en que la violación raramente ocurría anteriormente, Münkler considera posible afirmar que se trata de una violencia calculada y premeditada que forma parte de una estrategia militar, y que es independiente de los patrones tradicionales de comportamiento. Es decir, no se trata de una "costumbre" que se abre camino en la escena bélica, sino un comportamiento militar planificado. (Münkler, 2005: 85). En consecuencia, una "sexualización extensiva de la violencia es observable en prácticamente todas las nuevas guerras"(Münkler, 2005 86).

También otra especialista en la nueva forma de la guerra, Mary Kalder, a partir de su análisis de lo ocurrido en Serbia, arriba a esta misma conclusión de la inauguración de una guerra privatizada, a manos de fuerzas para-militares, que se vale de la desmoralización de las elites, la profanación de las mezquitas y lugares sagrados y la violación masiva de las mujeres como un método militar de máxima eficiencia. Con relación a las violaciones masivas, la autora entiende que, aunque han ocurrido en otras guerras, por el carácter sistemático que hoy asumen en centros de detención y en espacios determinados, hoy asumen un nuevo carácter como "estrategia deliberada" de guerra (Kalder Pos.1275 de 6020 en libro digital). A partir de un marco analítico en que destaca la globalización de la economía, las políticas de la identidad y el cosmopolitismo como dimensiones relevantes para la transformación de la guerra, es muy interesante la forma en que esta autora traza un paralelo entre tres patrones de violencia destinados a alcanzar el control territorial no por adhesión de la población y si por su desplazamiento por medio del uso de técnicas de contra-insurgencia que crean un ambiente de miedo e inseguridad permanente desfavorable para su permanencia en los territorios que ocupaban. Estos medios son la ejecución de atrocidades de una forma tal que se tornan de público conocimiento; la profanación y destrucción de todo lo que sea socialmente significativo, de los hitos de la historia y de la cultura, por medio de la remoción de sus huellas físicas, y de las edificaciones religiosas y de los monumentos históricos que permitan la reclamación territorial de un área particular; y, en tercer lugar, la deshonra por medio de la violación sistemática y el abuso. La autora concluye entonces apuntando a una diferencia clave entre las guerras del presente y las guerras convencionales del pasado: "Esencialmente, todo lo que se consideraba un efecto colateral no deseable 
e ilegítimo de la antigua guerra se transformó en el modo central de luchar en las nuevas guerras". "Estas guerras son racionales en el sentido de que aplican pensamiento racional a los fines de la guerra y rechazan los límites normativos" (Kalder Pos. 2450 de 6020 en libro digital).

En América Latina, varios equipos de investigación recientemente constituidos en diversos países de América Latina estudian hoy los crímenes sexuales ocurridos en los conflictos internos de los países y crean categorías forenses (Fernández, 2009; Otero Bahamón, Quintero Márquez y Bolívar, 2009) y jurídicas para aprehender, investigar y procesar ese tipo específico violencia como crímenes de guerra (Theidon, 2004; Uprimny Yepes, Guzmán Rodriguez \& Mantilla Falcón, 2008; Sondereguer, 2012; como ejemplos, entre otros). Un caso sobre el que existe abundante literatura que, inclusive, coloca su foco en el análisis de la violencia sistemática contra las mujeres indígenas como componente central del "conflicto interno" es el de Guatemala. Allí, fuerzas militares actuando para-estatalmente atacaron a las mujeres de los diversos pueblos mayas que forman la mayoría indígena de ese país, las sometieron a actos de extrema crueldad y a violaciones sistemáticas que se tornaron públicas y resultaron en la estigmatización y ostracismo de esas mujeres, como forma de disolver el tejido social, sembrar la desconfianza y romper la solidaridad comunitaria. En su interesante estudio del caso guatemalteco, Lily Muñoz (2013) hace referencia precisamente a una reveladora orientación encontrada en el Manual del Centro de Estudios Militares que comprueba lo que los autores citados más arriba afirman a respecto del carácter deliberado y calculado de la violencia sexualizada. Esa orientación contraría la regla humanitaria según la cual la violencia sexual en las guerras se encuentra proscripta y es condenable pues dice: "Las tropas empleadas contra fuerzas subversivas están sujetas a presiones morales y psicológicas diferentes de aquéllas que normalmente se encuentran en operaciones de guerra convencional. Esto resulta particularmente cierto debido a: La arraigada renuencia del soldado para tomar medidas represivas contra mujeres, niños y ancianos", y concluye enfatizando la necesidad de entrenar a los soldados para que ejecuten esa forma de violencia contra sujetos que no son agentes bélicos, enemigos armados, sino civiles y frágiles: "El soldado normalmente tiene gran aversión por las operaciones de tipo policial y por las medidas represivas contra mujeres, niños y enfermos de la población civil, a menos que esté extremamente bien adoctrinado en la necesidad de estas operaciones" (Manual del Centro de Estudios Militares s/d: 196, apud Muñoz 2013: 15-16. El énfasis es mío). 


\section{Cambio del paradigma territorial}

Una segunda dimensión contextual que se constela con los cambios de la modalidad de la guerra y vulnera el cuerpo de las mujeres es la transformación del paradigma territorial o territorialidad. En su historia de las formas de gobierno, Foucault presenta una periodización de las relaciones entre gobierno y territorio que aquí nos interesan. Según Foucault, en la época feudal y la modernidad temprana la forma de gobierno fue el gobierno del territorio o "dominio" de un lord feudal o rey, e incluía todas las cosas y personas contenidas en ese espacio delimitado. Solo después, a partir del siglo XVIII, el gobierno se transformó en gobierno de la población, es decir, de la administración del grupo humano asentado en el territorio. Esa mutación significó un cambio muy profundo en la concepción de la propiedad y la posesión que, ciertamente, debido a la contigüidad cognitiva entre cuerpo de mujer y territorio, resultó en una transformación profunda en las concepciones de género y sexualidad. Lo mismo ocurrió en la fase siguiente. Las técnicas disciplinarias y la exhibición ejemplar del castigo, situadas por Foucault en los siglos XVIII y $\mathrm{XIX}$, dieron paso a la sociedad de control en el siglo XX. ${ }^{1} \mathrm{El}$ ejercicio del poder pastoral fue un elemento crucial en esta transformación. Esta técnica, originaria del mundo judeo-cristiano de los tiempos bíblicos, es para Foucault la más eficiente de las tecnologías de poder, "una forma de poder simultáneamente individualizante y totalizadora" (Foucault, 1983: 213-214). La progresión de las modalidades de gobierno todavía continúa hasta un estadio final del control de la sociedad: el del poder como bio-poder, ejercido a través de la bio-política, con su correspondiente tipo de gobierno, esto es, el gobierno de la gente como seres biológicos por medio de la gestión de sus cuerpos. Políticas, en esta fase, son referidas a cuerpos (Foucault, 1997; 2004a; 2004b).

He defendido anteriormente que, en lo que respecta al gobierno y sus objetos de gestión, estamos hoy frente a la lenta emergencia de un tercer momento, en el que Estados compiten con agencias no-estatales, ambos ejerciendo su control sobre la población por medio de la técnica pastoral, es decir, como rebaño. En esta nueva etapa, el trazo distintivo de la población gobernada es su carácter extensible y fluido en forma de red y no más su fijación en una jurisdicción administrada por un Estado (Segato, 2007-a; 2007-b; 2008). El anclaje anterior de las poblaciones gobernadas dentro de un territorio fijo y nacionalmente delimitado va siendo transformado porque el foco del control se viene dislocando progresivamente hacia un rebaño humano móvil que corta a través de las fronteras nacionales. Por el efecto del paradigma del biopoder, la red de los cuerpos pasa a ser el territorio, y la territorialidad pasa a ser una territorialidad de rebaño en expansión. El territorio, en otras palabras, está dado por los cuerpos. Como nunca antes, por esta soltura de las redes con relación a la jurisdicción territorial estatal-nacional, con sus rituales, códigos e insignias, la
1. Ver, para una nueva comprensión de este proceso de transformación de las técnicas de disciplinamiento, Deleuze (1990). 
jurisdicción es el propio cuerpo, sobre el cuerpo y en el cuerpo, que debe ahora ser el bastidor en que se exhiben las marcas de la pertenencia.

Este último estadio introduce, por lo tanto, una mutación en la territorialidad misma, si entendemos territorialidad como una concepción particular, históricamente definida, del territorio. Los sujetos y sus "territorios" son co-producidos por cada época y por el discurso de cada forma de gobierno. Por lo tanto, los elementos constitutivos de una experiencia territorial no son fijos sino históricamente definidos. También se puede decir que esta forma contemporánea de territorialidad en red es un dispositivo a través del cual los sujetos son atraídos a la pertenencia, reclutados y marcados. La modernidad avanzada y la forma de vida colonizada por la economía de mercado tienen a liberar a los sujetos de un territorio vinculado al Estado y a producir poblaciones y territorialidades organizadas en red que atraviesan e interactúan con la jurisdicción estatal, pero que no coinciden completamente con ella. Como dije, agencias estatales y no estatales de gestión coexisten. Algunas agencias no-estatales se encuentran totalmente fuera de la legalidad, otras mantienen solamente una tensión con la institucionalidad de tipo estatal, siempre contornando y resolviendo su diferencia de proyectos e intereses. Las redes, por su lado, producen sus propios paisajes.

Para controlar el rebaño, las ahora agencias administradoras de redes deben intensificar tanto como posible su capacidad de control pastoral y sus biopolíticas, así como sus estrategias de marcación de los cuerpos para que exhiban su afiliación. El gobierno, por lo tanto, se ha separado de Estado, y gobiernos - en el sentido de administraciones - estatales comparten el espacio, coexisten y compiten, como he dicho, con gobiernos - agencias de gestión-no estatales, sean éstas empresarial-corporativas, político-identitarias, religiosas, bélico-mafiosas, etc.. Esto, coadunado con el biopoder, que coloca en los cuerpos el foco de la gestión, y la técnica pastoral, que conduce y produce rebaños por la producción y control de subjetividades, resulta en un nuevo paradigma de territorialidad, es decir, de la concepción y definición de lo que sea territorio. Esto tiene un fuerte impacto, por lo tanto, en la posición y el papel del cuerpo de las mujeres, por ser éste, ancestralmente, cognitivamente afín a la idea de territorio.

En el estadio anterior de la sociedad de control, el Estado implementaba técnicas pastorales y biopolíticas para producir sujetos dóciles. En la presente transición, las organizaciones gestoras propias de las redes poblacionales tienen a su cargo políticas de subjetivación. El aparato de Estado y su territorio es intersectado por estas nuevas realidades jurisdiccionales - como dije, empresarial-corporativas, político-identitarias, religiosas, bélico-mafiosas - que secuestran para sí una influencia importante en la toma de decisiones y en el acceso a recursos. Estas redes son 
internamente diversificadas e internamente estratificadas y cortan a través del territorio pre-existente, y son gobernadas por sus propias nomenklaturas, y debido a que los rebaños se desprenden de los territorios nacionales y de los paisajes fijos que previamente les servían como referencia y los aglutinaban, la subordinación y la cohesión entre sus miembros debe ahora expresarse exclusivamente por una imagen exterior unificada, es decir, la unidad debe ser espectacularizada y depende de claves perfomáticas. Se necesitan signos claros de pertenencia y de exclusión de lo no perteneciente. Lealtades a la red rediseñan el territorio como entidades proto-políticas y sus caudillajes se comportan como liderazgos para-estatales, co-existiendo con Estados nacionales en el control de las poblaciones. El tipo de lealtad que Habermas Ilamó de "patriotismo de la Constitución" (Habermas, 1994: 135) es reemplazado por un "patriotismo de las reglas de red", y los nuevos territorios se expanden constantemente en un proceso que se podría describir como una "anexión blanda". La red, a diferencia del Estado, no tiene una tradición bélica, en el sentido tradicional, pero se constituye conflictivamente. Su conformación y la definición de sus límites no tienen origen bélico, como en la historia de los Estados nacionales, pero su conflictividad es difusa, sin principio ni fin, una forma de existencia. Las redes pertenecen al ambiente formateado por el englobante paradigma de la política de la identidad (Segato, 2007-c) y proveen patrias territoriales substitutas para la gente común.

Como, por un lado, los territorios pasaron a ser carriles extensibles de identidad común e intereses compartidos dentro de cada red corporativa y, por el otro, los paisajes fijos debilitaron su papel como referencias para la identidad, la exhibición ritualizada de fórmulas expresivas de lealtad en red pasaron a ser cruciales. En este nuevo ambiente, las personas son las depositarias y portadoras del territorio y la cadena de personas pertenecientes a una red es una población. En otras palabras: el grupo de personas que co-pertenece a una red particular constituye, en sí mismo, el territorio y la población de esa red. Por eso podemos decir que los cuerpos mismos son el paisaje y la referencia, como portadores de los signos que componen la heráldica que emblematiza la propia existencia de la red, de este territorio en rebaño y siempre en expansión y consolidación.

El cuerpo y muy especialmente el cuerpo de las mujeres, por su afinidad arcaica con la dimensión territorial, es, aquí, el bastidor o tableta sobre el cual los signos de adhesión son inscriptos. Codificados atributos de pertenencia son burilados o anexados al mismo. Y en él, en especial en el cuerpo femenino y feminizado, los enemigos de la red graban con saña las señales de su antagonismo. Sí el énfasis es colocado en los signos exteriores de afiliación, únicos que expresan la unidad del grupo, necesariamente el disenso interior y la deliberación deben ser restringidos y reprimidos, presionando el paradigma territorial a afirmarse en la exhibición corporal de 
los signos diacríticos de una lealtad cohesionada - los tatuajes conspicuos de los miembros de las maras centroamericanas son un perfecto ejemplo de esta espectacularización de la pertenencia. Estas colectividades así marcadas no coliden porque son civilizatoriamente diferentes, como afirma la tesis huntingtoniana; al contrario, espectacularizan sus diferencias, las exacerban, porque compiten por recursos. Pertenecen al mismo paradigma territorial y político, y es mucho más lo que las une y las hace parte de un mismo mundo que lo que las divide. Sus signos espectaculares de cohesión y de antagonismo son solamente el escaparate, la inscripción pública de su existencia, así como de su cohesión corporativa. Su papel es expresar, más allá de cualquier duda, la unidad y lealtad interna del grupo y la capacidad de su clase dirigente, de sus élites, para controlarlo. La pertenencia tiene que ser externalizada, dramatizada. Cuando el dominio o jurisdicción no es un determinado feudo o nación, sino una congregación fluida, signos expresivos de adhesión y de antagonismo ganan importancia. La eficiencia performativa de una identidad ritualizada, una identidad como política, tienen relevancia crucial. El cuerpo obediente se torna, ahora, una función de un territorio cuya unidad no puede ser enunciada de otra forma. El tema central, dentro de la lógica de la política de la identidad, es menos una cuestión de persuasión que de representación.

El cuerpo inscripto como territorio y su afinidad con el biopoder es la forma última de control y completa la comprensión de la nueva territorialidad y sus demandas por lealtad y antagonismo ostensivos. Podría decirse que esta territorialidad es para-étnica. Esta nueva territorialidad no es otra cosa que el hidden-script y precondición de las guerras no convencionales, las nuevas formas de la guerra: el poder actúa en este estadio directamente sobre el cuerpo, y es por eso que, desde esta perspectiva, es posible decir que los cuerpos y su ambiente espacial inmediato constituyen tanto el campo de batalla de poderes en conflicto como el bastidor donde se cuelgan y exhiben las señas de su anexión. Como he dicho, el cuerpo femenino o feminizado se adapta más efectivamente a esta función enunciativa porque es y siempre ha sido imbuido de significado territorial. El destino de los cuerpos femeninos, violados e inseminados en las guerras de todas las edades dan testimonio de esto (Segato, 2003; 2006). Pero lo que la nueva territorialidad introduce es una vuelta de tuerca en esa afinidad, ya que el cuerpo se independiza de esa contigüidad y pertenencia a un país conquistado, y pasa a constituir, en sí mismo, terreno-territorio de la propia acción bélica. 


\section{Cambio correlativo en la cultura política o faccionalización de la política}

En sintonía con el cambio del paradigma territorial, se constata un cambio en el campo propiamente político, es decir, en el campo de la conflictividad de intereses y de la expresión de los antagonismos. En este nuevo contexto, la espectacularización de aspectos visibles de la diferencia - étnica, religiosa, racial, etaria, etc. - entre los antagonistas es más importante que los contenidos de la misma, por su propia instrumentalidad en la producción y reproducción de los conflictos que, en nuestro tiempo, se han constituido en un fin en si mismo por su carácter lucrativo para la industria bélica y para las compañías militares privadas (Azzellini, 2005; 2007; Münkler, 2005). En este nuevo trazado territorial, el valor reside en la pertenencia, en la afiliación, en la identidad política, en existir como rebaño, y los nuevos mecanismos corporativos en la economía y en la política benefician a quien accede a posicionarse y a marcarse comportamentalmente como miembro de la red.

Es necesario aquí advertir acerca de la diferencia diametral que opone mis apreciaciones a la célebre y archipromovida tesis Huntingtoniana, que es, como ésta, una tesis sobre la guerra. En ella, Huntington afirma que los pueblos se alinean en bloques antagónicos porque son diferentes, formulando una perspectiva que puede ser descripta como "determinismo étnico", que lo lleva a vaticinar un futuro de conflagraciones bélicas cuya causalidad radica en la diferencia de visión de mundo, sistema de creencias, valores y proyectos de sociedad de pueblos que conviven hoy más estrechamente que en el pasado. La diferencia civilizatoria es, para Huntington, el factor determinante de los antagonismos. Mi tesis (en Segato, 2007-a; 2007-b; 2008) es exactamente contraria a ésta, ya que afirmo que lo que hay, en el momento presente, es un lenguaje político-identitario en el que las posiciones con intereses - que describo como eminentemente territoriales, en el sentido descripto más arriba - en disputa se expresan por medio de marcas culturales exacerbadas e instrumentalizadas para este fin. El antagonismo se vale de un lenguaje étnico o religioso para simbolizarse y politizarse, la pauta de la política de la identidad domina, pero achata y vacía la densidad y profundidad de los contenidos de las diferencias civilizatorias, étnicas, ideológicas, doctrinales y teológicas substantivas (Segato, 2007-c). Hay una formateo étnico o religioso, siempre eminentemente identitario de la red de afiliación política, pero la disputa por dominio territorial y la globalización del capital y del mercado unifican todas las disputas. Por eso, las personas son obligadas y presionadas a alinearse en torno de los signos que demarcan estas jurisdicciones, a riesgo de que, de no hacerlo, no puedan ni expresar sus intereses ni encontrar medios para alcanzarlos.

El formateo de las identidades, como soporte de la política, tiene que ver también con lo territorial, lo que he descripto como el carácter territorial de la política hoy. La 
cultura política de las identidades es también territorial y hasta la política partidaria es hoy una cuestión de identidad y, por lo tanto, de territorio. La expansión de las identidades en red, las formas de anexión de miembros a redes identitarias o, en otras palabras, a redes como territorios, es hoy el tema y el proyecto de la política. Así como la religión hoy se prende al control fundamentalista de los cuerpos (y aquí coloco en el mismo plano el velo obligatorio en el islam y la obsesión anti-abortista entre los cristianos) por razones que son de soberanía jurisdiccional, de control del rebaño y de exhibición de ese control, y no de orden teológico, moral o doctrinal, de la misma forma, las razones de la política han perdido su foco en la dimensión ideológica y son hoy del orden de la cohesión y de las alianzas y, en ese sentido hasta la política partidaria es hoy "política de identidad" y su proyecto puede ser también comprendido como territorial, entendiendo la red de sus miembros como su territorio. El único valor buscado es el poder, y esta estrategia que prioriza la cohesión de las alianzas y su clara simbolización por encima de todas las dimensiones de la diferencia tiene como clave oculta la relación competitiva por el poder y un pacto vigente entre las facciones o partidos en conflicto con relación a las pautas que orientan su accionar para obtener porciones de poder, en el sentido de control jurisdiccional sobre recursos y personas. Poder éste que tiene en el control de los cuerpos el soporte donde puede simbolizarse y ejercer su pedagogía.

Cuando hablo de una clave oculta y de un pacto o acuerdo estratégico entre las facciones que compiten por poder, indico que todas ellas reconocen una reconfiguración del campo político en territorios marcados por la presencia de redes que se distribuyen entre sí recursos humanos, materiales y simbólicos específicos. Estos territorios tienen la característica de no ser democráticos ni socialmente homogéneos internamente, sino fuertemente estratificados, donde una cúpula o nomenklatura político-gerencial, doctrinario-religiosa o empresarial encuentra la forma de atesorar grandes recursos financieros que le permiten el monopolio del poder decisorio y un cerrado control, vigilancia y capacidad de expurgo sobre la totalidad de sus miembros. Esto es así porque solamente se puede acceder a esta lengua-franca de la gestión política si se genera internamente una estratificación tal que la disputa entre redes es una disputa entre sus nomenklaturas y la red es la masa de maniobra de esa cúpula para su proyecto de expansión del dominio territorial. No estoy afirmando que este tipo de estrategia no haya existido anteriormente. Lo que afirmo es que este paradigma de bajo perfil doctrinario y preponderancia del "proyecto de poder" sobre el "proyecto político-ideológico" se ha transformado en la gramática general que compatibiliza las acciones de las facciones políticas. Por razones que examinaré en seguida, las nuevas formas de la guerra responden también a esta misma lengua franca faccional, y se articulan perfectamente con este nuevo paradigma de la política. 


\section{Mafialización de la política y captura del campo criminal por el Estado.}

Me he referido hasta aquí a los cambios contextuales que configuran una esfera político-bélica en el mundo, con sus juegos de alianzas, antagonismos, facciones, sobre un cada vez más homogéneo telón de fondo resultante de la expansión del mercado global y del predominio del capital financiero. Ahora colocaré mi foco en el universo mafioso de la escena bélica difusa que se transnacionaliza, particularmente pero no exclusivamente, en América Latina. La violencia urbana, especialmente en las ciudades latinoamericanas, diseña escenarios bélicos difusos y en franca expansión, vinculados estrechamente a la informalización de la economía y al aumento vertiginoso del capital no declarado. Su contraparte es la exacerbación de la naturaleza dual del Estado, que podríamos describir también como paraestatalización del Estado, liminalidad de la operatividad estatal o cinismo de la excepcionalidad. Para trazar la relación entre la economía y la guerra informal de modalidad mafiosa, por tratarse de un universo no plenamente observable y al que accedemos por indicios dispersos, eventos de violencia que se presentan fragmentarios y de baja inteligibilidad, tenemos que valernos necesariamente de un modelo, es decir, de la apuesta en la existencia en una estructura de relaciones capaz de explicar los sucesos que en los medios son clasificados como "policiales" y en la gestión pública como "seguridad". Ante la evidencia de que el crimen organizado es hoy un continente en expansión y no parece haber medida pública capaz de contenerlo, nos vemos obligados a trascender esas casillas que confinan sus episodios en los márgenes del universo social y pensar de otra manera, hacer apuestas con relación a relaciones, conexiones, entre dimensiones de la vida social que van mucho más allá de los márgenes de la sociedad, de la categoría "policial" y del tema de la "seguridad pública".

El modelo que propongo parte por considerar que una interminable serie de negocios ilícitos produce sumas masivas de capital no declarado. Estos negocios son de muchos tipos: contrabandos diversos como el narcotráfico y de armas; el tráfico consentido y la trata engañosa de adultos y de niños; el tráfico de órganos; asimismo el tráfico de una cantidad inmensa de bienes de consumo legal que ingresan desde el exterior, incluyendo bebidas alcohólicas, drogas lícitas y partes de aparatos electrónicos, entre muchos otros productos que pasan a venderse en el comercio legal. También por el contrabando hacia el exterior de minerales estratégicos, piedras preciosas, maderas, y hasta animales exóticos. Aquí también suma mucho dinero la explotación de la prostitución en reductos francamente concentracionarios, donde se somete especialmente, pero no exclusivamente, a las mujeres al trabajo sexual esclavo. Otra fuentes de ese gran lago de capital sumergido, subterráneo, no declarado, son las casas de juego, los casinos, públicos o clandestinos, en los que es muy difícil medir los dineros que por allí circulan. También el pago de varias formas de protección mafiosa, como, por 
otra parte, de servicios de seguridad privada, cuyas contabilidades son siempre ambiguas pues es común contratarse, para los mismos, "en negro", el trabajo de policías en sus horarios fuera de servicio. El valor extraído no remunerado del cada vez más numeroso contingente de personas que realizan trabajo esclavo y servil, no pagado en la forma de salario declarado, así como en la diferencia entre los valores de pagos declarados y no declarados. Las varias formas de la evasión de impuestos, las varias magnitudes de la coima, así como los dineros que circulan en el tráfico de influencia y la compra de voluntades políticas. La corrupción que circunda todas las grandes obras, los emprendimientos intermediados por las mega-corporaciones contratistas, con conexiones transnacionales; la evasión de impuestos en los grandes negocios, los impuestos de los sectores ricos de la sociedad (no de las híper y estúpidamente vigiladas clases medias que viven de sus sueldos). Y la lista podría seguir. Nos convencemos, entonces, de que se trata de una segunda economía de porte y caudal extravagantemente inmenso. En el subtítulo "La conexión perversa: la economía del crimen global" de Fin de milenio, último volumen de su trilogía sobre la Era de la información, Manuel Castells (1999) hace una reseña estimativa de este bulto de capital de origen criminal, y dice, por ejemplo, que la Conferencia de la ONU de 1994 sobre el Crimen Global Organizado estimó que solo el narcotráfico ya rendía cifras anuales mayores que las transacciones globales de petróleo. Eso nos da una idea de la importancia de esa segunda economía, de la que podemos suponer que duplica, especularmente, o sobrepasa la primera economía, que circula a cielo abierto. La informalidad de la economía hoy es un continente inmenso, en el que participan banqueros, grandes empresarios y actores pertenecientes a las "buenas familias". No podría ser de otra forma, dada la enorme masa de caudales que allí se administra. Desafortunadamente, lo que vemos en los noticieros es la soldadesca oriunda de las ranchadas pobres y no blancas, la leva reclutada por la persuasión, por la necesidad de los desposeídos o por la fuerza, para ser carne de cañón en la primera línea de fuego a la que son mandados los peones, los soldados rasos, de esa organización gigantesca que atraviesa todos los estratos y niveles económicos de la sociedad.

Si consideramos que el papel del Estado, con sus leyes y normativas de diversos niveles, es proteger, en primer lugar, la propiedad, inclusive por encima de la protección de la vida, es decir, si recordamos que el valor jurídico por excelencia en un mundo en que el pacto central de los Estados es su pacto con el capital y que el Estado cumple este papel mediante el monopolio de lo que se concibe como "violencia legítima", es decir, aquella violencia ejercida por los agentes estatales que actúan en la seguridad pública, diremos, entonces, que el Estado dedica una proporción considerable de sus fuerzas y de la violencia legítima de que dispone a proteger la propiedad. Será por tanto inevitable la pregunta: ¿y qué fuerzas y qué tipo de violencia protegen la cuantiosa y enormemente variada propiedad en el nivel subterráneo de la "segunda economía"? Llegamos, a través de esa pregunta, a postular la existencia de dos rea- 
lidades: una Primera Realidad, constituida por todo aquello regido por la esfera del Estado, todo aquello declarado al Estado, visible en las cuentas de la Nación y en las páginas de internet de la Transparencia en Gestión Pública, las propiedades inmuebles residenciales, comerciales e industriales compradas o heredadas; los impuestos recaudados; los sueldos públicos y privados, los pagos "en blanco"; todo lo producido y comercializado; las empresas y sociedades de lucro; y ONGs registradas, etc. Para su protección, ese universo cuenta con las fuerzas policiales y militares, instituciones y políticas de seguridad pública, sistema judiciario y carcelario que protegen ese caudal legítimo, legal. Por otro lado, en el subsuelo de ese mundo de supuestas transparencias, se encuentra lo que en mi ensayo sobre Ciudad Juárez (2006) llamé "Segundo Estado", y que hoy prefiero llamar Segunda Realidad, pues es una realidad especular con relación a la primera: con bulto de capital y caudal de circulante probablemente idéntico, y con fuerzas de seguridad propias, es decir, corporaciones armadas ocupadas en proteger para sus "dueños" la propiedad sobre la riqueza incalculable que en ese universo se produce y administra.

No podemos entender la violencia como nos la presentan los medios, es decir, como dispersa, esporádica y anómala. Tenemos que percibir la sistematicidad de esta gigantesca estructura que vincula redomas aparentemente muy distantes de la sociedad y atrapa a la propia democracia representativa. Y, si pensamos un poco más, concluiremos que necesariamente esa estructura tiene una extensión global y una importancia política, es decir, que interfiere en la política e influencia los gobiernos, como también es interferida por éstos, tanto en las cabeceras nacionales como en los centros imperiales. En el ámbito nacional, porque su impacto es determinante en los pleitos electorales y sus vencedores quedan cautivos de los pactos que celebraron para elegirse. $Y$ en el ámbito global porque, por un lado, prestigiosos bancos del Norte lavan el dinero que produce y acumula la segunda economía y no es posible investigarlos y procesarlos con todo el rigor de la ley, allá, en el mismo Norte, ya que, como afirmó en 2013 el propio Fiscal General de los Estados Unidos, Eric Holder, los actos de corrupción y fraude cometidos por los ejecutivos de los bancos norteamericanos no pueden ser judicializados debido al tamaño de esas instituciones y su incidencia en las economías nacional (de los Estados Unidos) y global. Estamos aquí frente a la duplicación del Estado y la llana aceptación de la intocabilidad y funcionalidad de la "segunda realidad". Es esta una muestra también de la interconexión entre los caudales que fluyen subterráneamente y los que fluyen en la superficie. Por otro lado, los siempre atentos estrategas del Norte ven también, en esta partición del control estatal, una nueva oportunidad para controlar los destinos de las naciones, y ciertamente se hacen presentes aquí, con agentes a servicio de intereses imperiales interviniendo en ambos lados de la realidad, es decir, tanto en los negocios sombríos y subterráneos como en las políticas represivas. La abertura y vulnerabilidad de los negocios subterráneos a la ingerencia de los servicios imperiales y su expertise es de mano doble: por debajo, a 
través de los acuerdos del mundo subterráneo, sus tráficos de capital y mercaderías ilícitas, bienes e influencias, como muestra la omisión declarada, que cité hace un momento, del Fiscal General de los Estados Unidos frente al hecho de que sus bancos lavan el dinero de los negocios sucios en América Latina; y, por arriba, en los servicios de asesoría para la represión.

Es vinculando estas dos evidencias que acabo de mencionar, la de la complicidad de los bancos del Norte con el lavado del dinero que arrojan los negocios mafiosos en el Sur, por un lado, y la de la oferta de instrucción para la represión de las pandillas por parte de expertos militares norteamericanos, que podemos afirmar que las formas nuevas de la conflictividad son puertas de acceso para el control de asuntos de fuero nacional en una vía de doble mano, como estoy diciendo, en ambos universos o "realidades", la Primera y la Segunda Realidad, como las vengo llamando aquí. Es por lo tanto indispensable pensar grande y conectar el nicho "policial", el "crimen" y los temas de la "seguridad pública", con el Estado y la política. No hay que conformarse con el menudeo de los epifenómenos ofrecido por los medios.

Una de las consecuencias de la existencia de una "segunda realidad", con su capital propio, sus "dueños" y sus negocios es la expansión de un campo bélico de características nuevas, difuso, de difícil aprehensión, que está afectando progresivamente la vida de las sociedades. Los métodos, las prácticas, son muy semejantes en los diversos países, se transnacionalizan, delatando la posible existencia de una agenda común, así como también de conexiones, migraciones de jefes que se desplazan con sus métodos, y de correos, atravesadores que relatan e instruyen sobre las nuevas tácticas. En América Latina, desde Centroamérica hasta la Argentina, hay un proceso de mafialización de la política que resulta en guerras del para-Estado mafioso y guerras de los Estados actuando siempre con un brazo para-estatal. Lo que está ocurriendo es una expansión vertiginosa de lo que podríamos llamar "esfera para-estatal", que siempre existe porque, en sus variedades, siempre está operativa, y que es inherente a la naturaleza del Estado, pero que ahora, nuevamente, amenaza con imponerse sobre la esfera estatal, ya no por el camino de un golpe militar, sino desde abajo y por una forma nueva de inflación de la dimensión para-estatal que ya habita dentro del Estado. Por otro lado, quienes actúan en hoy sumergidos en el para-Estado mafioso son en muchos casos los mismos agentes de la represión de los tiempos dictatoriales, a veces inclusive como recursos humanos de las empresas de seguridad privada, como también son la mano de obra mercenaria de las compañías militares privadas que actúan en las guerras transnacionales de hoy, como fue señalado por Azzellini.

La dualidad del Estado fue teorizada por Ernst Fraenkel en el ambiente de la Alemania nazista (1941). Allí el autor cita Toennies diciendo que la principal caracte- 
rística de todo Estado moderno es su naturaleza dual. La co-etaneidad de la regla y la excepción, como afirma Giorgio Agamben en su relectura de Schmitt, Benjamin y Kafka (2004), y también Eugenio Raúl Zaffaroni en su relectura de Gunther Jacobs (2006), es propia de todo Estado en toda y cualquier época, de paz o de guerra, de democracia y, claro, de autoritarismo. Esa estructura dual se debe a que ningún gobierno puede actuar sólo estatalmente, normativamente, y debe lanzar mano de agencias y acciones que Frankel describe como "prerrogativas" o discrecionales junto a agencias y acciones "normativas". Si bien en Estados autoritarios esa duplicación es más visible, en tiempos democráticos ella se encuentra igualmente operativa. Es imposible controlar o disciplinar una sociedad nacional, con toda su pluralidad de intereses y de grupos, sólo con las leyes constitucionales. El Ilamado "gatillo fácil", por ejemplo, es la consecuencia de que el policía en la calle tiene poder de juez. El agente estatal policial tiene poder discrecional para juzgar y evaluar si una situación ofrece peligro y, como consecuencia de su arbitrio, dar muerte a un ciudadano sin por esto tener que responder ante la ley. Esa "soberanía" en términos agambenianos, es decir, ese arbitrio o discrecionalidad que caracteriza el papel policial frente a la población representa un vacío de legalidad que es, sin embargo, legal, y constituye un hiato natural, inextricable e inseparable de la ley. Tal duplicidad de competencia propia del papel policial en la calle no es en sí otra cosa que la personificación de la estructura dual del Estado en la figura del policía, que ejecuta - en ejecuciones sumarias llamadas "extrajudiciales", prácticas "normales" en todo y cualquier país - sin que esta acción represente una ilegalidad sino una de las formas naturales de la duplicación del accionar estatal a través de sus agentes. Dualidad aquí entendida como su duplicación en un permanente accionar estatal y para-estatal. La aquí descripta es una, entre muchas, de las formas en que el Estado es legalmente dual y actúa para-estatalmente sin traicionar su normativa. Existen varias formas de duplicación, y todo un territorio liminal entre lo legal y lo criminal, un verdadero limbo que demuestra la naturaleza ficcional del Estado de derecho.

Si la Primera Realidad a la que me he referido ya contiene, en su accionar, ese tipo de desdoblamiento, de duplicación, la Segunda Realidad es toda ella operada por un Segundo Estado, marcado por la acción de corporaciones armadas propias, sicariatos organizados y conducidos por cabezas que actúan a nivel local, barrial, y otras más distantes, a gran distancia social por el bulto de capital que circula, y a distancias geográficas que no podemos verificar pero que podemos suponer por la recurrencia de ciertas tácticas, por la sistematicidad de su forma de operar en localidades distantes e inclusive cruzando fronteras nacionales y continentales. Como expliqué, el accionar de esas corporaciones armadas tiene por finalidad ocuparse del mercadeo ilegal y de la protección de la propiedad y del flujo de los capitales sumergidos, así como de la intocabilidad de este ambiente todo. Es, por esto, un Segundo Estado, con su economía, con sus leyes, fuerzas de seguridad y organización propia. El efecto, para 
2. Entrevista a Oslain Santana, jornal $O$ Globo, Rio de Janeiro, 19 de octubre de 2013. toda la sociedad, de la existencia subterránea de esos elementos es la expansión, muy actual, de un escenario bélico caracterizado por la informalidad, tipo de guerras no convencionalizadas, en las que las facciones en conflicto por la apropiación territorial de espacios barriales y personas, en general jóvenes reclutas que se agregan a sus fuerzas, no usan uniformes ni insignias y expresan su poder jurisdiccional con la ejemplaridad cruel a que hice referencia antes. Por otra parte, no hay un lenguaje jurídico para hablar de estas nuevas formas de la guerra. No están legisladas en ningún lugar. La Convención Contra la Tortura, por ejemplo, habla de la tortura a mano de agentes del Estado, pero allí practican la tortura los agentes de otro Estado, los miembros de otro tipo de corporaciones armadas. La segunda realidad es un campo incierto, un pantano inexplorado.

La situación de la propia democracia liberal representativa - la "democracia real" o "democracia realmente existente" - se ve necesariamente afectada en este complejo escenario. No es despreciable la reciente declaración pública de un importante alto jefe policial, jefe del Combate al Crimen Organizado de la Policía Federal brasileña, en la que afirma que no existe político, de partido alguno, que se elija sin contar con un fondo de campaña de origen ilícito. ${ }^{2}$ Periodistas investigativos de diversos países y autoridades policiales como la citada ofrecen descripciones que apuntan a la conexión indeclinable entre políticos de todos los partidos y las mafias, con sus aportes indispensables a los fondos electorales de los procesos políticos sacramentados por el Estado. Esto coloca un signo de interrogación permanente sobre la estructura misma de la democracia representativa de masas y el orden "democrático", que no pueden defenderse ni de su propia sombra para-estatal ni del capital en su doble flujo: su flujo en los circuitos de la Primera Realidad y su flujo en los circuitos de la Segunda Realidad, ambos interconectados por adherencias irrigadas capilarmente por vasos sanguíneos muy bien surtidos. Esta situación diseña una escena de inmensa inestabilidad y anomia estatal que, sin embargo, emana, como he dicho, de la propia estructura del Estado. Y esa anomia abre las puertas a una belicidad que, como intento demostrar, se expresa de forma particular en la violencia ejercida sobre el cuerpo de las mujeres.

Tendemos a buscar, de forma casi automática y guiados por una racionalidad instrumental, los fines de la violencia de baja inteligibilidad de la que tenemos noticia, como es la violencia de género en las situaciones bélicas. Indagamos la dimensión instrumental de la violencia. Nos preguntamos "para qué", cuando deberíamos, como ya he argumentado anteriormente, rastrear en estos crímenes la dimensión expresiva. Toda violencia tiene una dimensión instrumental y otra expresiva. En la violencia sexual, la expresiva es predominante. La violación, toda violación, no es una anomalía de un sujeto solitario, es un mensaje de poder y apropiación pronunciado en sociedad. La finalidad de esa crueldad no es instrumental. Esos cuerpos vulnerables en el nuevo 
escenario bélico no están siendo forzados para la entrega de un servicio, sino que hay una estrategia dirigida a algo mucho más central, una pedagogía de la crueldad en torno a la cual gravita todo el edificio del poder. Enseñar la mirada exterior con relación a la naturaleza y a los cuerpos; producirse como seres externos a la vida, para desde esa exterioridad dominar, colonizar, expoliar y rapiñar es un elemento central en el entrenamiento militar que se ha exacerbado en las guerras del presente. El orden económico-militar, actuando en un escenario informal y subterráneo, parece depender de procesos de desensitización extrema y sin límites, del desmonte deliberado y sistemático de toda empatía humana, y, actuando en un universo escasamente normalizado como es el de la Segunda Realidad, de la exhibición de crueldad como única garantía del control territorial.

Formas de castigo amedrentadoras aplicadas a los más jóvenes para atraparlos en una leva forzosa instalan el terror, con su truculencia, entre las gentes de las periferias pobres de las grandes urbes y muestran que hay un caldo de cultivo del cual emana una amenaza clara para toda la sociedad; son señales disimuladamente emitidas a voz en cuello para anunciar que un peligro se cierne sobre el orden y previsibilidad de la existencia. Un signo de interrogación planea ahora sobre los códigos y las convenciones que dan estabilidad a las relaciones entre las personas. En otro lugar (Segato, 2013) me he referido a este proceso de "mafialización de la república" con la imagen del "Huevo de la Serpiente", título de la película sobre los orígenes del nazismo del gran director sueco Igmar Bergman. Este tipo de crueldad expresiva, denotativa de la existencia de una soberanía para-estatal que controla vidas y negocios en un determinado territorio es particularmente eficaz cuando se aplica al cuerpo de las mujeres. Este "método" es característico de las nuevas formas de la guerra no convencionales, inauguradas en nuestras dictaduras militares y guerras sucias contra la gente, en las guerras internas, en las guerras llamadas "étnicas", en la soldadesca asalariada de las empresas militares privadas, en el universo de los sicariatos que trabajan para las mafias, y en el accionar para-estatal de las fuerzas estatales de seguridad en tiempos de "democracia real". Antes, en las guerras hoy consideradas convencionales, desde el mundo tribal hasta las guerras formales entre Estados del Siglo XX, la mujer era capturada, como el territorio: apropiada, violada e inseminada como parte de los territorios conquistados, en afinidad semántica con esos territorios y sus cuerpos como territorio mismo. Era un efecto colateral de las guerras. En ella se plantaba una semilla tal como se planta en la tierra, en el marco de una apropiación. Pero la violación pública y la tortura de las mujeres hasta la muerte de las guerras contemporáneas es una acción de tipo distinto y con distinto significado. Es la destrucción del enemigo en el cuerpo de la mujer, y el cuerpo femenino o feminizado es, como he afirmado en innumerables ocasiones, el propio campo de batalla en el que se clavan las insignias de la victoria y se significa en él, se inscribe en él la devastación física y moral del pueblo, tribu, comunidad, vecindario, localidad, familia, barriada o pandilla que ese cuerpo femenino, 
por un proceso de significación propio de un imaginario ancestral, encarna. No es ya su conquista apropiadora sino su destrucción física y moral lo que se ejecuta hoy, destrucción que se hace extensiva a sus figuras tutelares y que me parece mantener afinidades semánticas y expresar también una nueva relación rapiñadora con la naturaleza, hasta dejar solo restos. Ese huevo de la serpiente que está siendo incubado, cuya existencia se revela en varios epifenómenos, es el proyecto histórico de un nuevo orden en el cual el mal es la regla.

Todavía, quiero advertir que, en mis análisis, yo no considero el gozo ni hablo del móvil del odio. No uso, por ejemplo, la expresión "crímenes de odio", porque es una explicación monocausal y porque alude al fuero íntimo, emocional, como causa única. Sugiero que el contingente agresor tiene interés en significar su pertenencia a una corporación armada, a una pandilla de sicarios, a una mara. Es un cálculo: para ser parte, será necesario ofrecer algunas demostraciones de capacidad letal y cruel sin quebrantarse. Por lo tanto, el miembro de la corporación armada para-estatal será entrenado para lograr el descenso de su umbral de fragilidad y el aumento de la capacidad de crueldad sin sufrir ni vulnerarse. Se prepara para entrar en un mundo en el cual el sufrimiento es el modo de vida. Quiero decir, por lo tanto, que ese "soldado se sujeta a ese orden interesadamente, a partir de un cálculo de conveniencia". La crueldad es expresiva y se separa de lo instrumental; pero la opción por ella es instrumental. Es un cálculo con referencia a los beneficios codiciados que se derivan del pacto mafioso, que, como he afirmado otras veces, obedece y replica el pacto masculino. Por esta razón, es importante dejar claro que los crímenes sexuales, especialmente los de guerra, son de soberanía jurisdiccional y de discrecionalidad soberana sobre un territorio, y no "de odio". En este sentido, aunque la idea del "odio" del agresor a su víctima es fácil de aprehender y comprender, es necesario percibir sus limitaciones, precisamente derivadas de su facilismo. La atribución de semejante complejidad en el accionar de las nuevas formas belicistas de la masculinidad al sentimiento de "odio" es, como afirmé, una explicación reduccionista y simplificadora por ser mono-causal, en primer lugar, porque pretende dar cuenta de escenas de altísima complejidad, en las que se combinan dimensiones psicológicas y sociales - la estructura del patriarcado - con intereses empresariales y políticos - los negocios fuera de la ley y los pactos de la élite política; y, en segundo lugar, por tratarse de una explicación referida a emociones privadas, a los afectos de fuero íntimo como es "el odio", cuando en realidad estamos frente a un panorama guerrero configurado por intereses de órdenes que superan en mucho la esfera de la intimidad. La explicación mono-causal y de sentido común que atribuye al móvil del "odio" las agresiones letales de género, es decir, que define los feminicidios como "crímenes de odio", ha hecho un gran daño a nuestra capacidad de entender qué sucede en la variedad de crímenes de género. Causalidad, y peor aún, mono-causalidad es una manera extremamente superficial de tratar cualquier acción humana. 
Sobre la violación como método, insisto en que, en el nuevo contexto bélico, ella no es apropiación sino destrucción, es decir, la devastación física y moral de un organismo-pueblo. Es muy importante aquí hacer notar otra importante característica de este nuevo escenario de guerra: ese cuerpo en el que se ve encarnado el país enemigo, su territorio, el cuerpo femenino o feminizado, generalmente de mujeres o de niños y jóvenes varones, no es el cuerpo del soldado-sicario-mercenario, es decir, no es el sujeto activo de la corporación armada enemiga, no es el antagonista propiamente bélico, no es aquél contra quien se lucha, sino un tercero, una víctima sacrificial, un mensajero en el que se significa, se inscribe el mensaje de soberanía dirigido al antagonista. Y esa victimización de quien no es el contrincante tiene una eficacia mayor como espectáculo de poder, en su exhibición de barbarie y ferocidad, en su mensaje de prerrogativa de arbitrariedad soberana, en otras palabras, como expresividad de un supremacía anómica. Y es por eso también que, desde una perspectiva analítica convencional, este tipo de violencia resulta poco inteligible, al mismo tiempo que aquéllos a quienes el mensaje va dirigido lo interpretan de forma automática y sin mediaciones: saben que se trata del poder expresándose por detrás de la crueldad impune.

Si la violación a varones, por otro lado, es la feminización de sus cuerpos, su desplazamiento a la posición femenina, la violación de las mujeres es también su destitución y condena a la posición femenina, su clausura en esa posición como destino, el destino del cuerpo victimizado, reducido, sometido. La pedagogía de feminidad como sometimiento se reproduce allí. Cuando se viola tanto a una mujer como a un hombre, la intención es su feminización como marca definitiva e indeleble, y ese acto, a su vez, establece de forma inapelable la inescapabilidad de la matriz heterosexual como fundamento y primera lección de todas las otras formas de relación de dominación (Segato, 2003). En la lengua franca del género se habla allí, en ese acto de guerra, directamente de la captura jerárquica de la humanidad en la matriz binaria de opresores y oprimidos, dominadores y dominados. En ese universo bélico de baja codificación, el último nomos que parece imperar, en medio a un vacío normativo, es el nomos del poder, expresado en el lenguaje primero y último del género, de allí la importancia de las violaciones como acto central de esta nueva modalidad de la guerra. De esta forma, las guerras no convencionales, en la contramano de todas las campañas que las mujeres hemos emprendido y en muchos casos ganado en el campo legislativo, renuevan y enyesan el imaginario colectivo colonial-moderno que nos atraviesa y que confiere significado a la violación, o acceso sexual forzado, como daño moral indeleble a la víctima y a todos aquéllos que detentan la capacidad de tutela y custodia sobre su cuerpo - sus padres, hermanos, maridos, y las autoridades políticas que tienen a su cargo la jurisdicción territorial en que habitan. Este imaginario establece la relación jerárquica que llamamos "género" como estructura binaria y desigual por la cual la posición masculina secuestra para sí la plataforma de enunciación de verdades de interés universal llamada "esfera pública" y 
se coloca en la posición de sujeto paradigmático de lo Humano pleno y englobante, en un gesto que expulsa a la posición femenina a la calidad de margen, resto, particularidad, cuestión de intimidad (Segato, 2011-b; 2014). La agresión bélica sexualizada a mujeres y a niños, es decir, a aquéllos que no ocupan la posición del sujeto antagonista en la guerra, representa una agresión simultáneamente física y moral a cuerpos cuya existencia debe darse bajo custodia, es decir, que por definición son cuerpos tutelados. La falla en poder proteger esos cuerpos de la saña enemiga es un indicativo de quiebra moral, una de las formas más importantes de la derrota en un imaginario que es arcaico, ancestral. La producción y reproducción de la moral de la tropa es un elemento central en la formación para la guerra, y su manutención esencial para obtener la victoria sobre el enemigo. Por otro lado, no hay derrota del vencido sin que en ella participe su destrucción moral.

\section{Femigenocidio:}

\section{la dificultad de percibir la dimensión pública de los feminicidios bélicos}

Como he argumentado hasta aquí, en el tipo de guerra informal característica de la modernidad y el capitalismo avanzado, el cuerpo femenino y feminizado tiene un destino particular. En las guerras convencionales del pasado, se lo anexó, se lo inseminó masivamente, se lo incorporó como parte del territorio conquistado, distribuyendo su posesión entre los hombres y las familias, como cuerpo esclavo o servil, y como cuerpo concubino. En la actualidad, ha ocurrido una transformación de ese antiguo papel del cuerpo femenino en la escena de la guerra. En las guerras informales que se expanden en el presente, el cuerpo de las mujeres es torturado por medios sexuales hasta la muerte, a él se le destina la destrucción siempre mediante la utilización aunque no exclusiva - del abuso y la intrusión sexual por su carácter profanador de lo que debe ser resguardado. Como hemos dicho en otras ocasiones: "cuerpo de mujer, campo de batalla", pues en él se agreden, desmoralizan, amedrentan, desmovilizan y, eventualmente, derrotan las huestes de hombres a cargo de su vigilancia y protección, usando saña no conocida anteriormente contra víctimas no guerreras, no directamente involucradas en el trabajo de la guerra.

A partir de estas consideraciones, entonces, es posible afirmar que si bien todas las agresiones de género y los feminicidios obedecen a un orden cuyo patrón se establece en la época temprana de la vida, en el medio familiar, y atraviesa toda la vida social al organizarla según una estructura patriarcal que ordena el campo simbólico y orienta los afectos y valores, hay, asimismo, un tipo particular de violencia de género que involucra necesariamente tratamiento cruel y letalidad, y que se separa y obtiene especificidad. Si toda la violencia de género es estructural, y cobra vidas en números próximos a un genocidio sistemático y en una multiplicidad de escenarios, 
es indispensable, para los fines de las estrategias de lucha contra la victimización de las mujeres, es decir, para poder investigar y desarticular los agentes perpetradores del daño, entender que hay un tipo de violencia de género que se genera y transita por escenarios absolutamente impersonales. En otras palabras, aunque todos los feminicidios obedecen a un dispositivo de género y resultan del carácter violentogénico de la estructura patriarcal, el fin de la impunidad depende de una tipificación rigurosa, que trascienda en mucho la mera utilización del nombre "feminicidio" y que sea capaz de discriminar por lo menos dos tipos amplios o grandes clases dentro de esta clasificación general, a partir de la consideración del móvil inmediato que los desencadena o gatilla: aquéllos que pueden ser referidos a motivaciones de orden personal o interpersonal - crímenes interpersonales, domésticos y de agresores seriales -, y aquéllos de carácter francamente impersonal, que no pueden ser referidos al fuero íntimo como desencadenante, y en cuya mira se encuentra la categoría mujer, como genus, o las mujeres de un cierto tipo racial, étnico o social, en particular - mujeres asociadas a la corporación armada antagónica, mujeres de la otra vecindad, mujeres del grupo tribal antagónico, mujeres en general como en la trata. Estamos aquí frente a la agresión y eliminación sistemática de un tipo humano, que no responde a un móvil inmediato o gatillo que pueda ser remitido a la intimidad. Entre estos últimos pueden ser contadas las agresiones de género en el contexto de los nuevos tipos de la guerra, la trata de personas con su reducción a condiciones concentracionarias, y el abandono o subnutrición de bebés sexo femenino y niñas en los países asiáticos, entre otros. Este tipo de feminicidios, que sugiero llamar "femi-geno-cidios" (Segato, 2001-b; 2012), se aproximan en sus dimensiones a la categoría "genocidio" por sus agresiones a mujeres con intención de letalidad y deterioro físico en contextos de impersonalidad, en las cuales los agresores son un colectivo organizado o, mejor dicho, son agresores porque forman parte de un colectivo o corporación y actúan mancomunadamente, y las víctimas también son víctimas porque pertenecen a un colectivo en el sentido de una categoría social, en este caso, de género.

Puede constatarse, a este respecto, que en los países que han pasado o atraviesan alta conflictividad interna de varios tipos aumentan las cifras de la violencia letal contra las mujeres, esto indicaría que lo que eleva esas cifras es el aumento de los crímenes en contexto de impersonalidad y que, por lo tanto, hay una proporcionalidad directa entre guerra y aumento notable de feminicidios. Una muestra de 54 países y territorios con información sobre la relación entre victimario y víctima de feminicidios revela que la proporción entre violencias letales interpersonales es menor en los países con tasas de feminicidios más elevadas. Por ejemplo, en El Salvador y Colombia, países que están entre los que tienen mayores tasa de feminicidio, solamente tres por ciento del total de feminicidios son cometidos por un compañero actual o ex. Por otro lado, Chipre, Francia y Portugal (países con bajas y muy bajas tasas de feminicidio), asesinatos de mujeres por compañeros actuales o ex compañeros responden por más de 80 por 
ciento de todos los asesinatos (Alvazzi del Frate, 2011: 129-130). De la misma forma, se puede constatar que entre los países marcados por altas tasas de violencia letal, las mujeres son más frecuentemente muertas en el espacio público, inclusive por gangs y grupos organizados (Segato \& Libardone, 2013). Infelizmente, solo podemos hablar de tendencias, ya que es imposible hacer más precisiones, debido a que no hay todavía una consciencia en la programación de las preguntas que guían la extracción de datos para la confección de las estadísticas ni de que se deben separar los crímenes asociados a detonantes personalizables (domésticos, interpersonales, seriales, etc. ) de los crímenes genéricos realizados por colectivos o corporaciones armadas contra categorías de mujeres.

Los crímenes de "femigenocidio", de genus, genéricos tanto en el campo de los perpetradores como en el de las víctimas, plenamente impersonales y masivos, que, por sus características, se aproximan a la definición del genocidio, están aumentando en número y en proporción con relación a los interpersonales o personalizables. Sabemos esto, por ejemplo, con relación a países para los cuales sí hay alguna información que permite discriminarlos. Guatemala, El Salvador y México, en América Latina, y Congo dando continuidad a las escenas horrendas de Ruanda, son emblemáticos de esta realidad. En Congo, los médicos ya utilizan la categoría "destrucción vaginal" para el tipo de ataque que en muchos casos lleva a sus víctimas a la muerte. En El Salvador, entre 2000 y 2006, en plena época de "pacificación", frente a un aumento de 40\% de los homicidios de hombres, los homicidios de mujeres aumentaron en un $111 \%$, casi triplicándose; en Guatemala, también de forma concomitante con el restablecimiento de los derechos democráticos, entre 1995 y 2004, mientras los homicidios de hombres aumentaron un 68\%, los de mujeres crecieron en 144\%, duplicándose; en el caso de Honduras, la distancia es todavía mayor, pues entre 2003 y 2007, el aumento de la victimización de los hombres fue de $40 \%$ y de las mujeres de $166 \%$, cuadruplicándose (Carcedo, 2010: 40-42). Todos estos países son palco de una duplicación extrema del Estado y de un "conflicto interno" que en lugar de resolverse se transforma y adapta a través de las décadas de la historia reciente. La escena bélica informal de estos países es de alta intensidad. Llama también la atención otro cambio en la escena tradicional de los crímenes de género para esta región, asolada por la conflictividad informal en el período para el que se registran esas cifras: los asesinatos de mujeres por sus parejas y ex parejas ya no representan la mayoría (Carcedo, 2010: 49), y los crímenes de género en la intimidad van decreciendo en número notablemente. Por ejemplo, para el caso de Honduras, junto al mayor ritmo de aumento de los asesinatos de mujeres, solamente uno de cada cuatro de estos crímenes se ejecutaron en el universo familiar (Carcedo, 2010: 53). Esto demuestra que la impersonalidad es un trazo que se afinca en los crímenes de género, y que esto se encuentra en asociación con los escenarios de creciente conflictividad, es decir, de las nuevas formas de la guerra, caracterizadas por la informalidad. 
La resistencia a hacer esta distinción por parte de algunos sectores del feminismo acaba aliándose a lo que he calificado como "voluntad de indistinción" de los crímenes contra la mujer demostrada, por ejemplo, para el caso de Ciudad Juárez, por las fuerzas de seguridad, la autoridad judicial y los medios de comunicación. Esa voluntad de indistinción responde y a la vez realimenta la tendencia conservadora, muy fuerte en la opinión pública y en la mentalidad de las autoridades, al mismo tiempo que perpetuada por la estereotipia propia de los medios, de capturar todas las agresiones sufridas por la mujeres dentro del universo íntimo, de la domesticidad y de la interpersonalidad, remitiendo el móvil a emociones y afectos. Al ignorar y obscurecer, tanto en la tipificación como en las estadísticas y en la propia reflexión feminista, la existencia de crímenes de género plenamente públicos e impersonales, que involucran contingentes específicos o poblaciones, concernientes a la conflictividad y a las presiones de los intereses que afectan a la sociedad en general, protagonizados en el papel del agresor y la víctima por agrupaciones o contingentes - contingentes organizados y corporaciones armadas de hombres perpetradores, y contingentes o categorías genéricas de víctimas -, se contribuye a reproducir el estereotipo que encapsula a la mujer en una atmósfera de domesticidad y particulariza sus demandas, es decir, se perpetúa una ideología de la "mística" femenina.

La privatización, es decir, el confinamiento de todos los crímenes de género a la esfera de la intimidad, consumada en la negativa de los medios, las autoridades y algunos sectores muy influyentes del feminismo, a visualizar la existencia de un tipo particular de estos crímenes, que deben ser discriminados, tipificados e investigados en su especificidad y diferencia por medio de protocolos y procedimientos forenses, policiales y jurídicos específicos, se deriva y a su vez realimenta los estereotipos vigentes que trazan una equivalencia entre "femenino" e "íntimo". Estos estereotipos afectan negativamente las prácticas de investigación policial y jurídicas, así como la administración de una justicia capaz de contemplar la queja de las víctimas: 1. Por un lado, contribuyen para que los crímenes contra las mujeres continúen no siendo percibidos por la opinión pública como ocurrencias plenas de la esfera pública por derecho propio, pues todos los tipos de crímenes contra las mujeres se encuentran contaminados, en el imaginario colectivo, por la atmósfera del espacio de intimidad, es decir, la domesticidad nuclearizada privatizada propia de los tiempos modernos (Segato, 2011-a). De esta forma, cuando los miembros de una corporación armada, sea ésta formada por agentes estatales actuando de manera para-estatal, o una corporación armada para-militar o milicia, agreden sexualmente por medio de violación y abusos el cuerpo de una mujer que han detenido o secuestrado, se puede decir que "sexualizan" ese sujeto, es decir, lo empujan y capturan en la esfera de su intimidad y despolitizan la agresión, lo reducen al campo de las relaciones de estatus desiguales propio del patrón de género y lo alejan de la posibilidad de una justicia plenamente pública. Cuentan con la complicidad de un imaginario colectivo en el que sexualidad 
y ley pertenecen a esferas separadas e irreconciliables, lo sexual al orden privado, íntimo y doméstico, y la ley a la esfera pública de interés universal y general. Eso hace que, a pesar de la prédica del movimiento feminista y de la existencia de diversas leyes al respecto, haya siempre una resistencia difícil de vencer cuando se trata de situar los delitos de orden sexual en el plano universal del interés general de la sociedad.

Frente a una escena bélica informal y difusa en expansión, que opera con métodos mafiosos, configura un universo para-estatal de control y captura progresivamente la vida social y la política, es necesario introducir en la retórica jurídica y en la consciencia de la opinión pública la centralidad y el significado de las formas nuevas de victimización del cuerpo femenino en las estrategias de manutención de un orden basado en la dominación arbitraria y soberana sobre la vida de las personas y sus territorios. Localizar y desarticular este dispositivo de dominio es una tarea urgente.

Abstract: New wars, characterized by informality, unfold today in a liminal space that can be defined as parastatal because is controlled by armed corporations with the participation of state and nonstate military personnel. In that expanding sphere of parastatality, violence against women is not a collateral damage of war any more but it has become a strategic objective of this new war scenario. This article examines the historical transformations around the informalization of war and points at the centrality obtained by a "pedagogy of cruelty" against those who do not play the role of armed antagonists in the fighting - women and children.

Key words: New wars, non-conventional war, gender violence, femigenocide, territoriality, parastatal sphere.

\section{Referencias}

Agamben, Giorgio. Estado de excepción (homo sacer II). Valencia: Pre-Textos, 2004.

AlvaZzI DEL Frate, Anna. When the victim is a woman. In: Geneva Declaration Secretariat, 2011, pp. 113-144. <http://www.genevadeclaration.org/fileadmin/docs/GBAV2/ GBAV2011_CH4.pdf>.

AZZELLINI, Dario. El negocio de la guerra. Tafalla, Navarra: Editorial Txalaparta, 2005.

- Mercenarios y nuevas guerras. Entrevista en la Revista Nómada, Universidad Nacional de General San Martín (UNSaM). Argentina, Año 2, n. 8, Dic. 2007.

CARCEDO, Ana (Coord.). No olvidamos ni aceptamos: femicidio en Centroamérica 20002006. San José de Costa Rica: Cefemina y Horizons, 2010.

CASTElls, Manuel. La era de la información. v. 3: Fin de milenio, México: Siglo XXI, 1999. 
COPELON, Rhonda. Crímenes de género como crímenes de guerra: integrando los crímenes contra las mujeres en el derecho penal internacional. McGill Law Journal, Nov. 2000.

DELEUZE, Gilles. Society of control. L'autre journal, n. 1, Mai 1990.

FERnÁndeZ, Mirko Daniel. Protocolo sobre violencia sexual contra mujeres asesinadas em masacres perpetuadas por grupos de autodefensa durante el período 1997-2003, y factores que determinan el registro de este tipo de violencia por parte del INML y CF. Bogotá: Instituto Nacional de Medicina Legal y Cuerpo Forense, 2009.

Foucault, Michel. Sécurité, territoire, population. Cours au Collège de France 19771978. Paris: Seuil, 2004-a.

Naissance de la biopolitique. Cours au Collège de France 1978-1979. Paris: Seuil, 2004b.

_. Il faut défendre la societé. Cours au Collège de France 1975-1976. Paris: Seuil, 1997.

The subject and power (Afterword). In: Dreyfus, H. \& RABINOW, P. (Eds.). Michel Foucault. Beyond structuralism and hermeneutics. Chicago: University of Chicago Press, 1983, pp. 208-228.

FRAENKEL, Ernst. The dual state: a contribution to the theory of dictatorship. New York; London; Toronto: Oxford University Press, 1941.

HABERMAS, Jurgen. Consciencia histórica e identidad postradicional. In: HABERMAS, Jurgen. Identidades nacionales y postnacionales. Madrid: Tecnos, 1989.

KALDOR, Mary. New and old wars. Organized violence in a Global Era. 3. ed. Cambridge, UK: Polity Press, 2012.

MüNKLER, Herfried. Las guerras del siglo XXI. Revista Internacional de la Cruz Roja, n. 849, 2003, p. 7-21.

—. The new wars. Cambridge, UK: Polity Press, 2005.

MuÑOz, Lily. Mujeres Mayas: genocidio y delitos contra los deberes de la humanidad. Guatemala: Centro de Acción Legal en Derechos Humanos (CALDH), 2013.

ODIO BENITO, Elizabeth. De la violación y otras graves agresiones a la integridade sexual como crímenes sancionados por el derecho internacional humanitario (crímenes de guerra). Órgano Informativo de la Comisión de Derechos Humanos del Estado de México (Codhem), Mayo/Jun. 2001, p. 98-112. 
Otero Bahamón, Silvia; Quintero Márquez, Viviana; Bolívar, Ingrid. Las barreras invisibles del registro de la violencia sexual en el conflicto armado colombiano. Revista Forensis, Bogotá, 2009, p. 335-349. <http://www.medicinalegal.gov.co/index.php?option=com_wrapper\&view=wrapper\&Itemid=60>.

Segato, Rita Laura. Las estructuras elementales de la violencia. Buenos Aires: Prometeo y Universidad Nacional de Quilmes, 2003.

- La escritura en el cuerpo de las mujeres asesinadas en Ciudad Juárez. Territorio, soberanía y crímenes de Segundo Estado. México, DF: Ediciones de la Universidad del Claustro de Sor Juana, 2006.

La faccionalización de la República y el paisaje religioso como índice de una nueva territorialidad. In Segato, Rita Laura. La nación y sus otros. Buenos Aires: Prometeo, 2007-a.

En busca de un léxico para teorizar la experiencia territorial contemporánea. In Segato, Rita Laura. La nación y sus otros. Buenos Aires: Prometeo, 2007-b.

- Identidades políticas / alteridades históricas. Una crítica a las certezas del pluralismo global. In SEgATo, Rita Laura. La nación y sus otros. Buenos Aires: Prometeo, 2007-c.

Closing ranks: religion, society and politics today. Social Compass, v. 55, 2008, p.207-219.

Género y colonialidad: en buscas de claves de lectura y de un vocabulario estratégico descolonial. In BIDASECA, Karina; VAZQUEz LABA, V. (Eds.). Feminismos y poscolonialidad. Buenos Aires: Ed. Godot, 2011-a.

- Femi-geno-cidio como crimen en el fuero internacional de los derechos humanos: el derecho a nombrar el sufrimiento en el derecho. In: FrEgoso, Rosa-Linda; Bejarano, Cynthia (Eds.). Feminicidio en América Latina. Mexico, DF: Centro de Investigaciones de Ciencias Sociales y Humanidades; Universidad Nacional Autónoma de México, 2011-b.

. Femigenocidio y feminicidio: una propuesta de tipificación. Revista Herramienta, n. 49, 2012.

- La nueva elocuencia del poder. In: Segato, Rita. La escritura en el cuerpo de las mujeres asesinadas en Ciudad Juárez. Buenos Aires: Editorial Tinta Limón, 2013.

_. La norma y el sexo: frente estatal, desposesión, patriarcado y colonialidad. In: Belausteguigoitia, Marisa; Saldaña, Josie (Eds.). Des/posesión: género, territorio y luchas por la naturaleza. México, DF: Pueg-Unam 2014 (de próxima aparición). 
Segato, Rita Laura; Libardone, Marlene. Derecho a una vida libre de violencia. In: MUGARIK GABE. Informe de las expertas para el Tribunal Internacional de Derechos de las Mujeres Viena + 20. Bilbao, Euskalherria, Espanha, 7 e 8 Jun. 2013. <www.mugarikgabe.org>; <www.tribunalderechosmujeres2013.blogspot.com.es>.

Sondereguer, María (Comp.). Género y poder. Violencias de género en contextos de represión política y conflictos armados. Buenos Aires: Editorial de la Universidad Nacional de Quilmes, 2012.

THEIDON, Kimberly. Entre prójimos. El conflicto armado interno y la política de la reconciliación en el Perú. Lima: Instituto de Estudios Peruanos, 2004.

United Nations Office On Drugs And CRIMe (UnOdC). Global study on homicide. Viena: Unodoc Research and Trend Analysis Branch, 2013. Division for Policy Analysis and Public Affairs, 2014.

UPRIMnY YePES, Rodrigo; GuzMÁn Rodríguez, Diana Esther; MANTILLA FALCón, Julissa. Violación sexual como crimen de lesa humanidad. Amicus Curiae presentado por la Organización No Gubernamental De Justicia (Colombia) ante la Primera Fiscalía Penal de Abancay. Lima: Asociación Pro derechos Humanos (Aprodeh), 2008.

ZAFFARONI, Eugenio Raúl. El enemigo en el derecho penal. Buenos Aires: Editorial Dykinson, 2006. 
